\title{
Estágio Profissionalizante e Formação em Psicologia: o Trabalho com Grupos como Dispositivo Formativo
}

\author{
Maristela de Souza Pereira \\ Universidade Federal de Uberlândia, MG, Brasil. \\ Jéssica Pagliarini Machado \\ Universidade Federal de Uberlândia, MG, Brasil. \\ Raíssa Neves Miranda \\ Universidade Federal de Uberlândia, MG, Brasil.
}

\author{
Andressa Fonseca Felice de Oliveira \\ Universidade de São Paulo, SP, Brasil. \\ Nágilla Regina Saraiva Vieira \\ Universidade Federal de Uberlândia, MG, Brasil. \\ Samantha Sousa Nascimento Cunha \\ Universidade Federal de Uberlândia, MG, Brasil.
}

Tatyanne Couto Flor

Universidade Federal de Uberlândia, MG, Brasil.

Resumo: O presente artigo visa discutir a formação do psicólogo, tendo como eixo de reflexão a prática com grupos no âmbito do estágio profissionalizante em Psicologia. A Psicologia Social do Trabalho é referência nos saberes e fazeres das atividades descritas ao longo do artigo, e auxilia na compreensão crítica sobre como se dão as relações sociais no mundo, estruturadas a partir do trabalho. Assume-se o trabalho como elemento fundamental para a compreensão do ser humano e da sociedade e direciona-se o foco de análise e compreensão das vivências humanas para como estas são emolduradas pela atividade laboral. Nesse sentido, reconhece-se que a forma de inserção dos trabalhadores e trabalhadoras no modo de produção será determinante das demais experiências e modos de existência acessíveis para esses e essas. A prática de grupos aqui retratada toma os participantes enquanto sujeitos ativos, e parte da noção de grupo como dispositivo, cujo desafio é criar junto aos membros novas configurações para suas experiências, descortinando outras possibilidades para pensar sua relação com o trabalho e consigo próprio, promovendo reorganizações subjetivas e objetivas. Desse modo, o grupo opera como promotor de novas formas de (se) ver e estar no mundo também para as estagiárias, gerando questionamentos sobre as práticas psi e sobre o papel e o compromisso social do psicólogo.

Palavras-chave: Psicologia Social, Trabalho, Grupo, Dispositivo, Estágio Profissionalizante.

\section{Professional Internship and Training in Psychology: Working with Groups as a Formative Device}

\begin{abstract}
This article aims to discuss the training of psychologists through the reflection on the practice with groups within the scope of the professional training in Psychology. Social Psychology of Work is a reference in the knowledge and practices of the activities described through the article, helping in the critical understanding of how social relations come about in the scope of work. This perspective perceives work as a fundamental element to understand human beings and societies, with focus on human experiences and how they are framed by work-related activities. In this sense, we recognize that the workers' place in the production system will be determinant of their other experiences and modes of existence accessible to them. The group practice depicted here considers the participants as active subjects. It also makes use of the notion of group as a device. The challenge is to jointly create new experience configurations with the members of the groups, revealing other possibilities to think about their relationship with their work and with themselves, and promoting subjective and objective reorganizations. Thus, the group also acts as a promoter of newways of seeing and being in the world for the trainees, raising questions about the practice, the role, and the social commitment of psychologists.
\end{abstract}

Keywords: Social Psychology, Work, Group, Device, Professional Training. 


\title{
Práctica Profesional y Formación en Psicología: El Trabajo con Grupos como Dispositivo Formativo
}

\begin{abstract}
Resumen: El presente artículo trata de discutir la formación del psicólogo, teniendo como eje de reflexión la práctica con grupos en el ámbito de la etapa profesional en Psicología. La Psicología Social del Trabajo es referencia en los saberes y hacer de las actividades descritas a lo largo del artículo, y auxilia en la comprensión crítica sobre cómo se dan las relaciones sociales en el mundo, estructuradas a partir del trabajo. Se asume el trabajo como elemento fundamental para la comprensión del ser humano y de la sociedad y se dirige el foco de análisis y comprensión de las vivencias humanas para mostrar cómo éstas son enmarcadas por la actividad laboral. En ese sentido, se reconoce que la forma de inserción de los trabajadores y trabajadoras en el modo de producción será determinante de las demás experiencias y modos de existencia accesibles para ésas y ésos. La práctica de grupos aquí retratados toma a los participantes como sujetos activos, y parte de la noción de grupo como dispositivo, cuyo desafío es crear junto a los miembros nuevas configuraciones para sus experiencias, descortinando otras posibilidades para pensar su relación con el trabajo y consigo mismo, promoviendo reorganizaciones subjetivas y objetivas. De este modo, el grupo opera como promotor de nuevas formas de (ver) y estar en el mundo también para las pasantes, generando cuestionamientos sobre las prácticas psi y sobre el papel y el compromiso social del psicólogo.
\end{abstract}

Palabras clave: Psicología Social, Trabajo, Grupo, Dispositivo, Formación Profesional.

\section{Introdução}

A formação em Psicologia surge em um contexto histórico no qual o discurso dominante está calcado em uma representação moderna da sociedade. Em seu nascimento, a Psicologia tinha bases "claramente positivistas e a-históricas" (Peretta, Silva, Naves, Nasciutti \& Silva, 2015). Esse fato influenciou profundamente seus paradigmas e teorias, que resistem ainda hoje em muitos cursos e nas práticas de psicólogos.

A busca pela verdade universal e a crença em uma realidade acabada são constituintes desse ideário moderno, que, na formação do psicólogo, legitima práticas hierarquizadas, em que o profissional tem total poder de falar sobre o outro, sobre sua constituição e supostas patologias. Dessa forma, o psicólogo pode manter práticas docilizantes e não empoderadoras, uma vez que sua formação, por vezes, não contempla questões políticas e se pretende neutra (Diehl, Maraschin, \& Tittoni, 2006).

Em contrapartida, há outras perspectivas de Psicologia que não ambicionam a neutralidade, por entender que esta é impossível. Buscam, ao contrário, compreender a importância dos processos históricos e políticos que permeiam a sociedade, contestando verdades absolutas e universais, além de problematizar as circunstâncias dadas como naturais em seus faze- res profissionais, tal qual discutem Diehl et al. (2006). Estas autoras propõem que o psicólogo assuma suas limitações e a necessidade de deslocamentos que possibilitem questionamentos sobre si e sobre seu lugar, auxiliando na constituição de um sujeito ético.

Frente a essas transformações, busca-se repensar também a formação e a prática do psicólogo, partindo de uma perspectiva crítica, a qual entende que não se pode privilegiar uma formação técnica, sem que esta seja atravessada pelas discussões políticas, inerentes a todo fazer profissional. Cabe assim questionar a quem a técnica de fato serve, se ela promove passividade ou empoderamento, se gera reprodução ou transformação das relações, das hierarquias, das desigualdades.

Temos em consideração que os processos educacionais e os processos sociais mais amplos são indissociáveis, e que, tanto a educação como a atuação profissional devem oferecer ao sujeito possibilidades criativas e emancipatórias. Deste modo, nos pautamos na perspectiva de Mészáros (2008), para quem a educação não deve formar para o mercado, mas para a vida, e os resultados do processo educacional, aqui compreendidos como a formação do psicólogo, devem possuir uma função libertadora e buscar transformar o sujeito em um agente político, que compreenda e possa afrontar o sistema de poder e econômico hegemônico. 
Entende-se que a formação acadêmica se constitui como uma possibilidade privilegiada para repensar os aspectos políticos e éticos da atuação profissional, tal qual discutem Reis e Guareschi, (2010), e que refletir sobre essa formação é fundamental, posto que a educação pode ser uma prática transformadora, ou reprodutora, o que trará reflexos sobre como se dará a ação profissional desses sujeitos. Dessa forma, o presente artigo visa discutir a formação do psicólogo, tendo como eixo de reflexão a prática com grupos no âmbito do estágio profissionalizante em Psicologia.

Para tanto, caracterizaremos inicialmente a perspectiva teórica pela qual nos guiamos, a proposta de trabalho com grupos, e a prática de estágio desenvolvida. Posteriormente, discutiremos como os encontros grupais, relatos, discussões teóricas e supervisões se entrelaçam a partir de uma concepção política do nosso fazer profissional, contribuindo para novas leituras de mundo, por parte dos sujeitos participantes dos grupos, das estagiárias e da supervisora de estágio.

\section{A Psicologia Social do Trabalho como norte teórico}

A Psicologia Social do Trabalho se ocupa da compreensão crítica sobre como se dão as relações sociais no âmbito do trabalho, com destaque para as vivências dos trabalhadores (Bernardo, Sousa, Pinzón \& Souza, 2015). Essa maneira de estudar o mundo do trabalho não se volta para as técnicas empregadas para desempenhar o trabalho ou para a produtividade que os trabalhadores podem gerar, interessando-se pela subjetividade dessas pessoas e pelas experiências vividas por elas enquanto trabalhadores e trabalhadoras.

Tal enfoque afasta-se sensivelmente da perspectiva adotada em geral pela Psicologia Organizacional e do Trabalho (POT), a qual volta-se prioritariamente para a gestão de pessoas, tendo como compromisso evidente atender aos interesses empresariais. Como discutem Bernardo, Sousa e Pinzón (2013), embora a Psicologia Organizacional tenha incorporado em seu discurso questões que apontam para aspectos mais gerais da sociedade e esteja se interessando mais pelos processos, e não apenas pelos resultados, ainda continua a tratar a configuração das tarefas e o modo como o trabalho é organizado dentro das empresas como não sendo passíveis de mudança. Sob essa ótica, resta ao trabalhador apenas se adaptar. À Psicologia, e aos psicólogos organizacionais, caberia exatamente o papel de garantir essa adaptação, amortecendo os conflitos entre os interesses dos trabalhadores e das empresas (Pereira, 2015).

Já a Psicologia Social do Trabalho, busca produzir questionamentos, promover reflexões dos trabalhadores sobre sua posição na relação capital-trabalho, fomentar a tomada de consciência sobre modos de enfrentamento frente ao sistema produtivo vigente. Essa perspectiva também compartilha a concepção de que é necessário que os psicólogos e psicólogas se perguntem sobre os aspectos políticos e éticos relacionados a suas intervenções, pois, se estiverem concentrados apenas na aplicação de técnicas, sem refletirem a quem de fato estas servem, trabalharão inevitavelmente em favor dos que possuem mais poder e da manutenção das diferenças sociais existentes, como denuncia Prilleltesnky (1994).

Um dos pontos de ancoragem da Psicologia Social do Trabalho é a tomada do trabalho como fenômeno dos mais importantes para a organização da sociedade, da vida dos sujeitos e da forma que se dão suas relações. A partir desta compreensão, assumimos o trabalho como elemento fundamental para a compreensão do ser humano e da sociedade através dos tempos, sendo uma tarefa que pertence exclusivamente ao homem e que possui um caráter social, por implicar na transformação da natureza e do sujeito. Trata-se de uma atividade proposital e consciente, tal qual analisado por Marx (2013).

Dessa forma, o trabalho é tomado como questão central na organização social, pois define as relações sociais, altera a composição geográfica, como, por exemplo, por meio da urbanização e exploração do campo, e é, também, um fator constituinte da identidade. Por conseguinte, o trabalho também está indissociavelmente ligado aos processos de saúde-doença, posto que a forma de inserção das pessoas no processo produtivo determinará as modalidades de desgaste físico e psíquico que incidirão sobre elas, o que se caracteriza essencialmente como uma forma de violência, tal qual discutido por Pereira (2017).

Bernardo, Souza, Silva \& Garbin (2013) apontam a necessidade de que o profissional de Psicologia esteja atento a essa questão, e ressaltam que seu olhar deve ser ampliado para além do âmbito meramente intrapsíquico, pois, se não considerar os determinantes sociais e as situações de trabalho potencialmente adoecedoras que afetam o sujeito, podem acabar contribuindo para naturalizar essas questões e as relações de exploração, tendo como consequência direta a 
responsabilização do trabalhador pelo próprio adoecimento. Tal postura evidencia um compromisso dos psicólogos e psicólogas com o descortinamento dos processos estruturais mais amplos aos quais estamos todos submetidos, e com a promoção de práticas que problematizem estas questões junto aos demais atores sociais, como propõem Bernardo e Pereira (2017).

Outro aspecto fundamental da Psicologia Social do Trabalho é que esta, ao estar comprometida com o estabelecimento de novas configurações e com as mudanças sociais, não segue um receituário pronto. Disso decorre que o psicólogo precisa abrir mão de sua onipotência e despir-se da capa de especialista que tudo sabe, para atuar também como aprendiz, para colaborar com a produção de novos saberes, novos inclusive para ele. Como apontam Bernardo, Souza, Silva e Garbin (2013), esse profissional precisa compreender a subjetividade como um processo coletivo, no qual ele também toma parte.

Por fim, entendemos que a Psicologia Social do Trabalho pode contribuir para que os trabalhadores desenvolvam uma consciência de seu papel em meio às situações de trabalho que vivenciam, bem como do conflito de interesses que permeia as relações entre as empresas e os sujeitos, que vendem para estas a sua força de trabalho. Em outras palavras, concebemos que a Psicologia Social do Trabalho desempenha um importante papel ao chamar atenção para o protagonismo dos trabalhadores enquanto agentes sociais, os quais podem, e devem, reivindicar novas conformações de trabalho para si e para o coletivo de trabalhadores.

\section{A ideia de dispositivo como norte para as práticas grupais}

Em consonância com a perspectiva da Psicologia Social do Trabalho buscamos pensar intervenções que apontem o caráter social dos processos psíquicos e que possibilitem a discussão dos fatores coletivos que se apresentam nas formas singulares de sofrimento, adoecimento e saúde. Sob esse enfoque, o grupo se mostra como ferramenta ideal de intervenção.

São diversas as modalidades de configuração grupal. Trabalhamos com a noção de grupo como dispositivo, tal qual apresentada por Barros (1993). Essa autora aponta que a individualização está presente massivamente no modo de funcionamento das sociedades capitalistas, o que remete a maneiras unitárias de compreensão dos sujeitos, limitando suas identidades às características autocentradas. Do mesmo modo, o indivíduo e o grupo foram pensados ao longo da história como dois polos antitéticos (opostos, contrários), reproduzindo uma lógica individualista, que teria por contrapartida uma totalidade maior, representada pela sociedade (Barros, 1994). Essa visão dual, apresentada pelos polos indivíduo/sociedade, pessoal/social, indivíduo/grupo, tem como consequência a ideia de totalidade sob a mesma forma individualizante, do que se depreendem práticas centradas no indivíduo, que promovem a reprodução dessa mesma lógica.

Blanch e Cantera (2008) retomam a concepção althusseriana de que cada modo de produção produz seu modo de subjetivação correspondente. No capitalismo, a subjetivação toma a forma do modo indivíduo, sendo produzidas de forma massiva subjetividades individuais. Todavia, como pondera Barros (1994), o modo indivíduo é apenas uma das formas de subjetivação possíveis, existindo outras modalidades de criação de subjetividades, consideradas enquanto multiplicidade de devires ${ }^{1}$.

Os modos de subjetivação, compreendidos como modos de existência e de se relacionar com o mundo, consigo mesmo e com os outros, são múltiplos, estão em constante transformação, e são vinculados às possibilidades ofertadas pelo meio social. O desafio, portanto, é criar junto aos participantes dos grupos novos devires, descortinar possibilidades outras, realizar reorganizações, produzir pluralidades. Como dispositivo, o grupo pode produzir novos agenciamentos, acontecimentos que antes não estavam previstos, pode propiciar outras formas de (se) ver e estar no mundo.

Enxergar o grupo como dispositivo é provocar deslocamentos do lugar em que somos colocados, é nos retirar daquilo que bloqueia a criação, é resgatar junto aos sujeitos a sua capacidade de se libertar dos códigos existentes que tudo explicam e conferem o mesmo sentido às diferentes experiências. $\mathrm{O}$ dispositivo é processo que movimenta, tensiona, desloca para o novo, provoca novas subjetividades, operando sentidos diversos (Barros, 1993).

Em consonância com essa perspectiva, o grupo é assumido como um processo, e não como estanque ou oposto ao sujeito. Isso significa considerar os movimentos voláteis da realidade, concebê-la, e a nós todos, enquanto configurações momentâneas, em constante

${ }^{1}$ Vir a ser, movimento ininterrupto de transformação e criação dos seres e das realidades. 
transformação. Entendemos o grupo como um espaço "onde não se buscam significados, mas se produzem outros sentidos" (Barros, 2013, p. 321). Nossas intervenções são então pautadas na problematização, na desindividualização e na experimentação.

Uma vez que o grupo possibilita ouvir o outro, permite, com isso, ouvir outros modos de existências, de subjetivação, novos modos de experimentar. Além disso, propicia que experiências que se acreditavam individuais possam ser vistas de outra maneira, proporcionando a abertura de novos caminhos de contato com o coletivo que somos.

Desse modo, os participantes podem ressignificar suas próprias vivências, antes tomadas como apenas particulares e exclusivas deles, e compreendê-las como parte de um processo social maior, se (re)encontrando nas falas dos demais participantes e na compreensão profunda das vivências relatadas por eles, que ecoam em sujeitos outros que também adoeceram ou experimentam sofrimentos variados, decorrentes dos processos de trabalho.

Ao pensarmos grupo e dispositivo, podemos refletir acerca do paradigma ético-estético-político (Barros, 2013), que permite a experimentação da subjetividade, pensando formas de composições inéditas. A via ética encontra-se na possibilidade de experimentação, de procura por alterar os processos já dados de subjetivação que separam os indivíduos do coletivo que os produzem. Já a estética se alia à ação/ criação para promover singularizações, retomando o caráter transformador do grupo para o surgimento de soluções inéditas, não previstas antes. A dimensão política é dada pela clareza de que o grupo não diz respeito apenas a uma montagem onde indivíduos diferentes foram colocados juntos, mas trata-se de um processo que permite questionar os mecanismos de organização social. Nesta perspectiva, o grupo tem como possibilidade a diferenciação e a promoção de resistência aos processos de massificação dos modos de subjetivação (Barros, 2013).

Por fim, o surgimento de outras possibilidades de subjetivação é possível por meio de rupturas feitas no decorrer dos encontros em grupo, onde as subjetividades atuais constituídas possam ser desarranjadas. Isso pode ocorrer com qualquer um dos participantes, sejam os trabalhadores, as estagiárias ou a supervisora. Assim, vislumbramos o grupo enquanto um espaço ocupado por diferentes, mas que não são desiguais, do que ressaltamos outra marca importante do nosso posicionamento no grupo: a busca por uma horizontalidade nas relações. Por isso, entendemos o grupo como fortalecimento e potencialização do coletivo, capaz de empoderar a cada um e a todos nós.

\section{O intercruzamento teórico-prático: caracterizando o estágio}

O estágio profissionalizante é uma atividade fundamental na formação acadêmica, entendendo que se estabelece uma relação dialética de ensino e aprendizagem entre o estagiário e supervisor (Nasciutti, \& Silva, 2014). Esta etapa possibilita que os estudantes iniciem seu exercício profissional entrelaçando sua história pessoal com a formação teórico-prática que o curso de Psicologia proporciona. O estágio é um espaço de elaboração emocional, intelectual e reflexiva precioso, uma oportunidade para se construir caminhos de um exercício profissional comprometido com a realidade social vigente, ancorado nos conhecimentos acadêmicos adquiridos.

Assim, concordamos com Maraschin e Tittoni (2002), para quem o estágio profissionalizante não é compreendido meramente como a aplicação de conhecimentos teóricos. Ele se torna um momento de reflexão sobre aspectos mais amplos, sobre o intercruzamento entre os processos de produção e reprodução social e as práticas onde nós, psicólogos, tomamos parte, bem como os atravessamentos desse processo macro na constituição de subjetividades, nossas e dos sujeitos a quem oferecemos nossos serviços.

A legislação que rege o estágio profissionalizante para os cursos de Psicologia considera esta atividade central na formação do psicólogo (Resolução nº, de 7 de maio, 2004). A Lei Federal $n^{\circ} 11.788$, de 25 de setembro de 2008, que regulamenta os estágios, entende que esse é um ato educativo que deve ser supervisionado e cumprido no ambiente de trabalho a fim de preparar o estudante para executar tarefas laborativas, desenvolver competências da atividade profissional amparadas no currículo acadêmico, visando à preparação para uma vida cidadã e produtiva.

Todavia, como bem expresso aqui, não há menção sobre a necessidade fundamental de se pensar o estágio para além da mera aplicação de técnicas e desenvolvimento de competências profissionais, no sentido de se compreender que ambas, técnicas e competências, são formadas dentro de uma lógica social e tendem a reproduzir essa mesma lógica. Como discute Bourdieu (1989, 2011 e 2012), há uma relação biunívoca entre as 
práticas sociais e o mundo social, onde esse condiciona as primeiras e aquelas reproduzem o último.

Assim sendo, um exercício primordial que deve ser levado a cabo nas atividades formativas, incluído o estágio, refere-se a pensar sobre qual mundo queremos produzir com nossas práticas e ações, questionando as teorias que alicerçam intervenções adaptativas e normativas. Nas experiências aqui compartilhadas, assumimos uma postura crítica para com a lógica do capital, no interior da qual a educação tem como função a produção de conformidades e consenso, tal qual denuncia Mészáros (2008). Buscamos desvelar essa lógica, que reforça o modo indivíduo e opera pela busca da manutenção da hierarquia social.

Considerando a necessidade de se ter práticas críticas no âmbito da Psicologia Social do Trabalho, temos organizado um estágio profissionalizante intitulado "Estágio em Saúde do Trabalhador" no Instituto de Psicologia da Universidade Federal de Uberlândia (UFU), o qual vincula-se ao eixo formativo Psicologia Clínico-Social. O período aqui focalizado abrange quatro semestres (2015/2016), cujas práticas grupais foram desenvolvidas junto à Clínica de Psicologia da referida instituição, que é um órgão conveniado ao Serviço Único de Saúde (SUS), fazendo parte da Rede de Atenção à Saúde no município de Uberlândia. As experiências que discutimos no presente artigo foram construídas no âmbito de três diferentes articulações institucionais: com o setor de Reabilitação Profissional do Instituto Nacional do Seguro Social (INSS), com o Centro de Referência em Saúde do Trabalhador (CEREST) e com o Hospital de Clínicas da UFU. As autoras são a supervisora-orientadora de estágio e seis estagiárias que tomaram parte nesses projetos, em semestres letivos distintos.

Com relação à caracterização do estágio, sua principal atividade é a promoção de grupos de escuta e acolhimento, tendo sido pensado inicialmente a partir de três propósitos: propiciar a formação teórico-prática-ético-política das estagiárias²; atender às demandas dos sujeitos e das instituições envolvidas; e criar um campo de atuação em Saúde do Trabalhador no Instituto de Psicologia da UFU. Nesse sentido, objetiva-se a capacitação de futuros profissionais para intervenção em Saúde do Trabalhador e nas políticas públicas relacionadas a esse campo, a instrumentaliza- ção para o trabalho com grupos e a formação de profissionais críticos, com olhar atento para as questões sociais e coletivas, evitando a psicologização de problemas que são estruturais, ao mesmo tempo em que possuam a sensibilidade para compreender como esses incidem sobre os sujeitos e promovem sofrimento.

No estágio, oferecemos acolhida e um espaço de fala e de escuta aos trabalhadores em processo de sofrimento psíquico, buscando resgatar suas experiências pessoais e profissionais, relacionadas ao trabalho e aos impactos físicos, subjetivos e sociais decorrentes desse, ou da sua falta, com vistas ao enfrentamento de sua condição atual e dos impasses gerados por ela. Operamos por meio do compartilhamento de experiências, da busca sobre os aspectos em comum e singulares, da reflexão sobre alternativas viáveis e da ampliação do repertório de ação destes sujeitos.

O estágio foi delineado abarcando prática e teoria simultaneamente, de modo que é necessário um conhecimento prévio sobre o campo Saúde do Trabalhador ${ }^{3}$ e uma capacitação teórica para manejo de grupos, realizada antes e durante as práticas. As atividades consistem, portanto, na formação teórica, na prática grupal, no relato dos grupos; e na supervisão, também em grupo, com a docente supervisora-orientadora do estágio.

Os grupos ocorrem semanalmente, contando com oito a dez encontros, com duas horas de duração cada, sendo geralmente conduzidos pelas estagiárias, sob a supervisão da docente. Os participantes são encaminhados pelas instituições parceiras.

\section{Sobre o que aprendemos coletivamente nessas experiências}

Nessa seção apresentaremos algumas reflexões sobre como as vivências do estágio que, seja na condução dos grupos, seja nas supervisões semanais, possibilitaram novas formas de se pensar o papel do psicólogo e também as questões relacionadas ao mundo do trabalho. Ouçamos inicialmente o que dizem as estagiárias.

\section{Vozes das estagiárias}

O estágio em Saúde do Trabalhador nos proporcionou a desconstrução do papel do psicólogo que até então estava presente no nosso imaginário, moldado

\footnotetext{
${ }^{2}$ Usamos o termo no feminino, pois, até o momento, apenas discentes do gênero feminino tomaram parte nessa atividade.

${ }^{3}$ Um dos pré-requisitos para o estágio é ter cursado a disciplina optativa Saúde do Trabalhador ou o Curso de Extensão em Saúde do Trabalhador, oferecidos pela supervisora.
} 
principalmente por um viés clínico e individualizante presente no nosso currículo acadêmico.

Diehl et al. (2006) apontam que o trabalho do psicólogo social se efetiva mais por um posicionamento político do que pela circunscrição do lugar de atuação. Apontam ainda o questionamento e a problematização como caminhos para a abertura de possibilidades de produção de sentidos, por meio do deslocamento dos lugares outrora ocupados. Nesse âmbito, a implicação e a suspensão de teorias possibilitam uma abertura maior para atenção às vivências. Conforme orientam os autores supracitados, trata-se de olharmos para as situações e compreendê-las como construídas e, portanto, passíveis de mudança, para que o nosso saber não sirva para a dominação e manutenção do status quo, ao cair na classificação e na reificação dos lugares sociais ocupados pelo sujeito. Trata-se assim de promover trocas e desenvolvimento de potencialidades. Pudemos entender que as técnicas são nossas aliadas, assim como a teoria, mas que também precisamos estar abertos para colocá-las em questão na hora da prática, a qual vai se delinear a partir do encontro. Por mais que façamos planos, tenhamos um roteiro para nos amparar e coloquemos um objetivo para o trabalho, tudo isso só se efetivará a partir das possibilidades do concreto, dadas pelo encontro com os sujeitos participantes, com as expectativas desses, e com a riqueza e complexidade que surgem desse encontro. Obviamente que não se trata de uma postura anárquica, mas sim de uma abertura reflexiva, com vistas a evitar cristalizações.

Entendemos que historicamente a Psicologia muitas vezes negou seus aspectos políticos e se distanciou da realidade social. No entanto, o estágio em Saúde do Trabalhador nos permitiu entender e contextualizar as necessidades e o sofrimento dos sujeitos que participaram dos grupos, assim como contextualizar nossas próprias intervenções, que não existem descoladas da realidade e que produzem efeitos sobre ela. Buscamos evitar a psicologização dos problemas sociais enfrentados por eles e acompanhá-los no processo de identificação das forças que atravessam o cenário do trabalho no capitalismo e de seu empoderamento para retomarem novos rumos frente ao adoecimento e à atual condição física. Ao mesmo tempo, nos questionamos frequentemente sobre essas forças que atravessam igualmente o nosso trabalho enquanto estagiárias e psicólogas, e que influenciam nossos entendimentos sobre os sujeitos com quem trabalhamos, uma vez que nós também estamos inseridas nesse cenário.

Cabe destacar que essa noção de empoderamento não é concebida por nós enquanto um ato de concessão externa, de habilitar alguém para, o que poderia gerar relações hierárquicas e manipulatórias. Tampouco é considerada como um ato que depende unicamente do sujeito, como se esse tivesse plena autonomia para fazer suas próprias escolhas. Tomamos o sentido de empoderamento apresentado por Paulo Freire, para quem esse refere-se a um processo que ocorre na esfera coletiva, em que as pessoas, pela interação com outros agentes sociais, constroem um pensamento crítico em relação ao mundo, favorecendo o reconhecimento de suas capacidades pessoais e sociais e possibilitando a transformação das relações de poder (Baquero, 2012).

$\mathrm{O}$ efeito despolitizador trazido pelo olhar cientificista positivista que a Psicologia construiu possibilitou o surgimento de práticas que entendiam as questões humanas por um viés abstrato e distante do âmbito social (Reis, \& Guareschi, 2010). O estágio, ao contrário, proporcionou uma visão histórica das questões relacionadas ao trabalho, destacando os aspectos ideológicos presentes nas relações pessoais e institucionais que se configuram no âmbito das empresas.

Pautamos nossa atuação na concepção de que é impossível separar Psicologia e política, já que as práticas psicológicas lidam com sujeitos que vivem em um determinado local e em um momento histórico, sendo uma construção política (Reis, \& Guareschi, 2010). Não foi possível nos mantermos neutras ao ouvir os relatos das condições de trabalho dos participantes, de como eles adoeceram pelo trabalho ou sofreram algum acidente que impossibilitou o retorno ao mercado até o momento. Assim, tivemos que questionar nosso papel como psicólogas e também como cidadãs.

É importante destacarmos que o psicólogo, como um agente político, vive alguns tensionamentos na formação e nas práticas. Um desafio importante que experienciamos no estágio foi de abrirmos mão de certezas e ocuparmos um lugar de incompletude. Como discutem Zanella e Sais (2008) é necessário assumir a complexidade do real, o que significa assumir também que o processo de produção de conhecimento é igualmente complexo, e admitir que os conhecimentos da Psicologia não são uma verdade única e nem um passaporte que garante $\mathrm{o}$ acesso direto à verdade dos e sobre os sujeitos. 
Para nós, isso significou compreender que não há garantia nas técnicas, que estas não se constituem como uma salvaguarda a priori para nossa atuação. Devemos contar com uma postura problematizadora e reflexiva, que nos ajude a questionar os fundamentos capitalistas, neoliberais e individualizantes que estão por trás de muitas técnicas e práticas psicológicas. Isso quer dizer superar a tentação de armar-se de respostas prontas e, de acordo com Zanella e Sais (2008), superar o existente para projetar-se em direção a devires, para a reinvenção da própria existência e das nossas práticas profissionais.

Os momentos de supervisão e análise das práticas, amparados por meio dos registros que fizemos dos encontros, nos mobilizaram novas sensibilidades, ampliando os focos de potencialidades e reflexão. Essa experiência nos possibilitou vivenciar a postura que Reis e Guareschi (2010) definem como a de um

profissional (não isento) inundado de subjetividades, (não separado) misturado à ação política, que (não se distancia) se aproxima dos sujeitos [...], que entende que as técnicas e instrumentos devem ser colocados a favor de sua práxis e que não deve se tornar escravizado por eles (p. 23).

No que tange à Saúde do Trabalhador, o estágio portou a possibilidade de conhecer um campo de atuação que busca compreender os processos de saúde e doença dos grupos humanos, gerados na sua relação com o trabalho, o qual é visto como propiciador de adoecimento, caso não seja ofertado em condições dignas. Pudemos entender esse campo de atuação enquanto uma alternativa a outras modalidades de fazer do psicólogo, que buscam intervir sobre os aspectos cognitivos do sujeito, para que esses possam ter uma melhor aceitação das práticas de dominação a que são submetidos, e que não questionam as relações produtivas capitalistas que promovem os adoecimentos.

Desse modo, compreendemos vivencialmente a noção presente na Constituição, de que a saúde é um direito de todos, bem como o quanto estamos longe de efetivar esse direito para todas as classes sociais. Como apontam Santos e Lacaz (2011), cabe aos diversos profissionais e técnicos envolvidos no campo Saúde do Trabalhador, bem como aos trabalhadores e trabalhadoras, questionar e intervir sobre as formas laborais adoecedoras.
Todavia, esses mesmos autores apontam que uma das maiores dificuldades da Saúde do Trabalhador é a fragilidade política dos atores que deviam ser os pilares das demandas e proposições nesse campo, qual sejam: os próprios trabalhadores. Essa questão se fez presente em inúmeros momentos dos encontros grupais, pois os participantes por vezes não se identificavam como trabalhadores/trabalhadoras, e também não compreendiam inicialmente seus sintomas ou patologias enquanto gerados na relação com o trabalho.

Nesse sentido, o formato de atendimentos em grupo foi muito útil, pois levava os participantes a reconhecer nas falas dos seus colegas os sentimentos e a exploração a que também estavam submetidos. Puderam promover reflexões sobre as origens do seu adoecimento, o qual, anteriormente, era entendido pelos trabalhadores como algo individual, consequência de uma fraqueza pessoal, para compreendê-lo como uma forma de denúncia dos abusos a que eram submetidos pelas empresas, que operam a partir da lógica de produção e do lucro a qualquer custo.

Pudemos também observar durante as atividades do estágio, como o rompimento da vinculação com trabalho causa sentimentos de exclusão, solidão, inutilidade e insegurança financeira daqueles que vivenciam essa situação. Em diversas falas constatamos tristeza pela impossibilidade de continuar a exercer a função que desempenhavam, e que foi a causa do adoecimento. Após alguns encontros, essas falas ainda apareciam, agora, porém, com o reconhecimento do quanto aquela atividade era desgastante e ultrapassava os limites do corpo, causando assim, o adoecimento.

Outro aspecto que destacamos foi o sofrimento relatado de forma geral pelos participantes que se encontravam vinculados ao serviço de Reabilitação Profissional do INSS, decorrente do preconceito por estarem afastados do trabalho e recebendo auxílio previdenciário. Tal preconceito está atrelado a uma visão moralizante, que tem origem na ideologia capitalista, de que as pessoas são condenadas a trabalhar em quaisquer situações que se encontrem e ao mesmo tempo aceitar qualquer tipo de tarefa e condições de trabalho e remuneração que lhes sejam oferecidas.

O contato com a área da Saúde do Trabalhador foi muito importante, enquanto profissionais que ambicionam uma atuação crítica e consciente de seu papel na sociedade. Sabemos do desafio que isso traz, posto que, como apontam Minayo-Gomez e Thedim-Costa 
(1997), a "Saúde do Trabalhador é um campo potencialmente ameaçador, onde a busca por soluções quase sempre confronta com interesses econômicos arraigados e imediatistas, que não contemplam os investimentos indispensáveis à garantia da dignidade e da vida no trabalho" (p. 23).

Por meio dessa atuação entramos em contato com conhecimentos referentes às questões trabalhistas, entendendo os direitos e deveres do trabalhador. É importante destacar que, nas disciplinas obrigatórias do curso de graduação, tal assunto não é abordado de forma efetiva e, às vezes, nem sequer é mencionado. Além disso, estávamos diante de sujeitos que em grande parte dos casos adoeceram por condições de trabalho que não garantiam tais direitos, afetando suas subjetividades também em decorrência do adoecimento físico.

Vivenciar o estágio nesse campo confrontou-nos com a impossibilidade de separação entre Psicologia, ética e política, pois pudemos vislumbrar que nossas intervenções são formas de ação que afetam a vida dos sujeitos, e que qualquer intervenção realizada com os sujeitos produz efeitos no coletivo, tal qual situam Reis e Guareschi (2010).

Por fim, salientamos que a intervenção grupal se mostrou condizente com as questões que discutimos até aqui, configurando-se como uma ferramenta potente para a produção de reflexões e deslocamentos, não apenas dos participantes, mas também de nós mesmas, abrindo brechas para pensarmos outros modos de atuação e outros mundos possíveis. A experiência foi desafiadora, no sentido de nos estimular a vivenciar os grupos enquanto coparticipantes, portanto passíveis também de confrontação com nossos modelos prévios. Isto gerou angústias relacionadas aos deslocamentos necessários para uma atuação menos psicologizante e mais aberta para as múltiplas possibilidades dos encontros que se deram ali. Estas dificuldades também dizem respeito às inseguranças sobre como e quando nós, enquanto estagiárias, deveríamos intervir, movendo-nos novamente do lugar de controle e previsão dos acontecimentos. Em função de como entendemos o grupo, enquanto dispositivo, as respostas para estas hesitações só foram encontradas durante os encontros e nas reflexões geradas a partir das supervisões. Portanto, o trabalho com grupos porta inúmeras possibilidades de diferenciação e resistência aos processos de massificação e reprodução, de modo a interromper a repetição e permitir "o aparecimento do plano de forças de produção a partir do qual tal realidade se constituiu" (Benevides, 2005, p. 23).

Conforme ouvíamos relatos de trabalhadores em condição de adoecimento proveniente de uma grave violação de seus direitos básicos, necessitávamos trabalhar continuamente para não nos prendermos em posições paralisantes, pensando em possibilidades de deslocamento dos lugares de angústia e revolta, para a luta e enfrentamento das dificuldades apresentadas. O trabalho grupal se colocou, portanto, como uma forma de atuação política.

Dessa forma, a modalidade de grupo, foco do estágio, foi fundamental para nossa formação, pois possibilitou também nosso deslocamento em direção a uma compreensão da atuação do psicólogo como fundamentalmente inserida dentro de um contexto histórico e social. O grupo, visto como dispositivo de produção de novos agenciamentos para os trabalhadores e trabalhadoras participantes, configurou-se assim como um dispositivo viabilizador de novas perspectivas para nós, no que tange à compreensão da nossa prática profissional, das possibilidades que ela abarca e também da dimensão política que a atravessa. Assim, o estágio, momento tão esperado durante os primeiros anos da graduação, mostrou-se nesse caso como uma porta de entrada para o contato com o campo do fazer profissional, que é afinal seu objetivo, e também como um momento de reflexões profundas sobre esse mesmo campo. Como já situamos anteriormente, o estágio profissionalizante é uma prática pedagógica da maior relevância. Isso ficou evidente para nós, posto que, além de nos instrumentalizar tecnicamente para a prática profissional, também nos descortinou a necessidade de reflexão contínua sobre essa mesma prática.

Por isso nos referimos ao grupo, no título desse artigo, como dispositivo formativo: ele abriu para nós novos horizontes para pensar a intervenção, superando as práticas psicológicas centradas apenas no atendimento clínico-individual, ainda que também tenha nos preparado para exercitá-las, caso esta demanda se apresente a nós, mas em um enquadre que não desconsidere as determinações sociais que incidem com toda sua força sobre os sujeitos singulares. Em outras palavras, conseguimos compreender a produção social do sofrimento, ainda que esse seja sentido de forma singular pelo sujeito que chega até nós e demanda nosso trabalho. 


\section{Voz da supervisora}

A vivência inicial do estágio com grupos foi desafiadora não apenas para as estagiárias, mas também para mim. Embora tivesse experiência no trabalho com grupos, não havia até então deixado a condução desses a cargo de estagiárias, sem estar presente aos encontros. Inicialmente tive receio do que poderia acontecer, pois o manejo grupal é bastante diferente dos atendimentos clínicos individuais, que são o eixo principal de formação do curso ao qual nos vinculamos. Todavia, com o decorrer dos encontros, fomos construindo um modo de trabalho pautado pela confiança mútua e sustentado pelas leituras, discussões teóricas e pelas reflexões coletivas nas supervisões, que se mostrou profícuo e frutífero.

Outra questão que me desafiou no início foi o fato de que este estágio estava atrelado ao eixo clínico-social. Minha área de atuação é a Psicologia Social. Mas, como o eixo comporta também a ênfase clínica, vivenciei a dúvida se conseguiria trabalhar com as estagiárias a articulação de um olhar social com as vivências singulares de sofrimento que certamente seriam trazidas pelos participantes.

Outro aspecto desafiador foi construir um estágio em Psicologia Social do Trabalho, quando, no Projeto Pedagógico do curso, a ênfase é nomeada como "Psicologia e Processos de Gestão", a qual abarca a formação técnica para a atuação profissional em empresas, assim delineada sob a justificativa da necessidade de atendimento às demandas do mercado. Todavia, em consonância com Ramos (2012), cabe questionar se o papel da universidade é formar para o mercado ou para a sociedade. Fico com a segunda opção.

A própria formatação do projeto pedagógico, definida por ênfases e voltada ao desenvolvimento de competências ${ }^{4}$, está calcada em uma racionalidade pedagógica de produção em série de profissionais para pronta inserção no sistema produtivo, sem questionamento das regras de funcionamento desse. A proposta do estágio em Saúde do Trabalhador visa justamente a se configurar como uma contraprática, como uma forma de denúncia e resistência a esse modelo ideológico de reprodução educacional e social.

Além dessas questões orientadoras, tive que lidar com outras, de ordem mais técnica. Por exemplo, me perguntava como poderia promover reflexões e orientar ações intermediadas pelas estagiárias, mesmo não vivenciando in loco as produções do grupo. Entretanto, também com o correr das supervisões, fui compreendendo que minhas intervenções sobre a atuação das estagiárias eram orientadas não somente pelas produções do grupo, mas também pelas mobilizações que surgiam em mim ao ouvir os relatos produzidos por elas sobre os encontros. Assim, as reverberações emocionais produzidas nas estagiárias, e também em mim ao ouvir seus relatos, me possibilitaram compreender a dinâmica instalada nos encontros grupais, e também os movimentos e angústias vivenciadas por elas nesse trabalho, podendo oferecer suporte também nesse sentido. Posso perceber que o formato do estágio foi se delineando aos poucos, em um processo de invenção que, embora contasse com uma proposta claramente delimitada, foi através das práticas e supervisões que ganhou uma dimensão objetiva. Como salientam Maraschin e Tittoni (2002), essa possibilidade de produção de práticas inovadoras cria brechas por onde podem passar a invenção e o invisível, criando fissuras que levam à desestabilização dos poderes legitimados.

Olhando em retrospectiva, consigo apontar hoje alguns anteparos que foram fundamentais para a minha constituição como supervisora do estágio em Saúde do Trabalhador. O primeiro foi certamente minha experiência anterior com grupos. Ter vivenciado a experiência grupal como facilitadora foi imprescindível para poder supervisionar e dar sustentação à prática das estagiárias nessa modalidade de atendimento. Outro sustentáculo importante foi o referencial teórico sobre grupos com o qual trabalhamos, pois além de ser uma fonte de orientação a ser buscada em momentos de incerteza, também é um significador poderoso para as experiências constituídas nos encontros dos grupos e nos encontros da supervisão. Para além do suporte teórico para o manejo de grupos, houve a necessidade de buscar aprofundamento sobre diversos temas focalizados nos diferentes percursos dos estágios. Assim, nós, estagiárias e supervisora, estudamos textos e lemos pesquisas sobre assédio moral no trabalho, reabilitação profissional, contaminação por metais pesados, trabalho em enfermagem, que nos auxiliaram na compreensão das vivências objetivas relatadas pelos sujeitos, as quais remetiam a essas questões. Essa articulação entre o par teoria e prática foi decisiva para

${ }^{4}$ Para atendimento às exigências do Ministério da Educação (MEC). 
a caracterização do estágio como prática pedagógica efetiva. Como resultado, capacitou as psicólogas em formação para o manejo de grupos, bem como para a compreensão de que a intervenção não ocorre apenas em uma via única, do psicólogo para o outro, mas em múltiplas direções: do outro sobre nós, de nós para as instituições onde atuamos e vice-versa, dessas sobre os sujeitos, e assim por diante.

Uma ferramenta que se mostrou essencial em todo esse processo foi a escrita. Uma das atividades do estágio consistia no relato das estagiárias sobre cada encontro, o qual devia ser feito individualmente (embora os grupos fossem conduzidos sempre em duplas). Do mesmo modo, a supervisora produzia um relato das supervisões, ao término dessas. O relato produzido pelas estagiárias não se tratava de uma mera reprodução do que havia acontecido nos encontros, mas visava à constituição de um momento de reflexão sobre esses acontecimentos, a partir de um distanciamento e do deslocamento de posição, de alguém que tomou parte para alguém que, ao relatar, está refletindo sobre eles. Ao escrever, era possível para as estagiárias ressignificar os eventos e também refletir sobre o que esses haviam produzido nelas, bem como sobre as intervenções que haviam oferecido (ou não) em resposta aos mesmos. Nessa mesma linha, o ato de relatar as supervisões, constituiu-se como uma espécie de diário de bordo, que, além de preservar os acontecimentos e situações e registrar impressões e reflexões, possibilitou a ampliação da minha compreensão sobre todo esse processo. Diehl et al. (2006) lembram que a escrita é um aspecto importante no processo de formação do psicólogo, e no caso dos relatos dos estagiários, serve como um processo de produção de inscrições, entendidas como novas experiências e não como mero transporte de ideias.

Uma questão com a qual por vezes tivemos que lidar foi com um movimento das estagiárias em se prender aos relatos, como se tivessem que relatar tudo o que tinha acontecido nos encontros. Machado (2014) aponta o cuidado necessário para que o relato não se torne uma descrição. Na nossa experiência, em algumas ocasiões precisei chamar a atenção das estagiárias a esse respeito, para que o relato não se convertesse em uma armadilha, no sentido de aprisionar a experiência delas, ao invés de ampliá-la. Desse modo, aos poucos, foi ficando claro que o que mais importava ali era o ato de relatar, ou seja, a experiência de registrar a experiência para substrato de novos significados, e não o relato em si.
Um aspecto que também tivemos que lidar em diversos momentos foi com a desconstrução da ideia de um suposto "distanciamento" necessário do psicólogo em relação aos participantes do grupo. Esse distanciamento pode facilmente levar a uma posição de saber, a qual muitas vezes era convocada pelos participantes do grupo, e em algumas situações acabava sendo assumida pelas estagiárias. Buscávamos então retomar o princípio da horizontalidade nas relações, presente no nosso referencial de trabalho com grupos, para construir novas possibilidades. Optamos sempre por suspender as posições cristalizadas, como proposto por Diehl et al. (2006). Obviamente não podemos ser ingênuos ao pensar que a busca de relações mais horizontais faz magicamente desaparecer esse lugar do imaginário dos sujeitos com os quais estamos em contato, e nem mesmo do imaginário dos estudantes ou dos psicólogos já formados. Ao contrário, é uma questão que necessita atenção e cuidado constantes, com vistas a despirmos a capa de um suposto saber legítimo, para nos colocarmos ao lado dos sujeitos, na busca de produção de novos modos de se relacionar, de resistir e de existir, como propõem Zanella, Levitan, Almeida e Furtado (2012): "ReXistências que reinventam a vida de cada um e, ao mesmo tempo, contribuem para a reinvenção das vidas de todos" (p. 260).

A outra fonte de sustentação para o trabalho nesse estágio, presente em todos os momentos, desde a seleção das estagiárias, passando pela escolha dos textos a serem discutidos, pelas instituições parceiras no estágio, e culminando na construção cotidiana das nossas intervenções e posturas nos encontros grupais e de supervisão, foi um olhar predominantemente social sobre a constituição dos sujeitos (nós aí inclusas) e sobre as problemáticas relatadas pelos participantes. Esse enquadre busca evitar as ciladas do psicologismo e das explicações puramente intrapsíquicas para as formas de sofrimento e adoecimentos humanos, as quais desconsideram as questões do contexto, das formações coletivas e do momento histórico que vivemos. Esta postura é traduzida por Ramos (2012), ao enfatizar que o psicólogo precisa estar atento às questões que ultrapassam e que atravessam as pessoas que procuram sua ajuda profissional, caso contrário, em vez de promover práticas emancipatórias junto a estas, acabará por contribuir para a perpetuação de seu ajustamento ideológico. 
Esse é um parâmetro basilar que tem guiado as análises e reflexões sobre as produções efetuadas pelos membros dos grupos e pelas estagiárias no processo de supervisão. Assim, uma questão que desde o início do estágio está posta é que nossas intervenções devem visar à problematização com os sujeitos sobre as questões estruturais e dos processos de opressão a que são submetidos em sua relação com o mundo do trabalho. Esta postura encontra eco em Bourdieu (2012), para quem a única forma de romper com esse ciclo é por meio da denúncia e da compreensão dos processos de dominação simbólica que incidem sobre todos nós. Em consonância com essa postura, as leituras e traduções geradas no processo de supervisão direcionam-se à busca de desvendar essas relações e fomentar reflexões que apontem para uma maior autonomia, tanto dos trabalhadores e trabalhadoras que participam dos grupos, quanto das estagiárias, tal qual expresso por Ramos:

A formação pressupõe uma dialética entre a adaptação do sujeito à realidade social e histórica existente e seu processo de busca por autonomia e singularidade, o que implica a transformação da própria realidade e, portanto, ao mesmo tempo, uma ruptura possível com o existente (Ramos, 2012, p. 155).

O que temos buscado através desse estágio é configurar uma práxis tanto clínica como social, com potencial transformador e emancipador para todos os envolvidos, de modo a produzir um empoderamento coletivo, pois, como salienta Mészáros (2008), não se pode vencer uma força social poderosa como é a ordem social do capital, pela ação fragmentada de indivíduos isolados. Alguns podem argumentar que essa disputa está perdida, ou que se trata de utopia, mas, novamente estamos de acordo com Ramos (2012), ao apontar que precisamos conferir um estatuto político à categoria do impossível, pois esse, também chamado utopia, é a história enquanto possibilidade.

\section{Em direção a novas possibilidades}

A partir dos percursos aqui explorados, compreendemos que o estágio profissionalizante se constitui como um ponto angular para a formação do psicólogo, a qual não se encerra com a graduação, mas tem lugar ao longo de toda a trajetória de atuação desse profissional. Tal trajetória, ao ser inaugurada com um aparato teórico-prático crítico e reflexivo, na forma de estágio, pode vir a se configurar de forma mais sustentada, problematizando os lugares comuns já dados e abrindo brechas para ações emancipatórias junto aos sujeitos aos quais nossas práticas se endereçam.

Para nós, o estágio se constituiu como uma oportunidade transformadora, tanto para os participantes dos grupos, para as estagiárias, e também para a supervisora, caracterizando-se como uma "contraprática" de subjetivação, viabilizando a construção de novas subjetividades, enquanto potencialidades de ação no mundo social. Para os trabalhadores e trabalhadoras que tomaram parte nos grupos, apresentou-se como uma possibilidade de construção de novos modos de estar no mundo, frente seu adoecimento e limitações atuais. Essas pessoas nos contaram, durante e no encerramento de cada um dos grupos, como mudaram seu jeito de pensar seu adoecimento e sobre novas ideias e projetos que começaram a desenvolver para si. Para as estagiárias, o estágio forneceu ferramentas para a intervenção profissional e constituiu-se como uma circunstância para (re) pensarem seu papel e os propósitos da atuação do psicólogo. Para a supervisora, foi a comprovação da viabilidade de práticas de resistência no âmbito da Psicologia e também a confirmação de que o ensino pode e deve se constituir como momento de reflexão e não como mercadoria, ou como mera instrumentalização técnica para o mercado. Para todos nós, foi uma experiência pautada pelas trocas e pelo compartilhamento de novos horizontes possíveis.

\section{Referências}

Baquero, R. V. A. (2012). Empoderamento: Instrumento de emancipação social?: Uma discussão conceitual. Revista

Debates, 6(1), 173-187. http://dx.doi.org/10.22456/1982-5269.26722

Barros, B. R. (2013). A afirmação de um simulacro. Porto Alegre, RS: Sulina/Ed. UFRGS.

Barros, R. B. (1993). Dispositivos em ação: o grupo. Cadernos de Subjetividade, 1(1), 97-106.

Barros, R. B. (1994). Saúde e loucura 4: Grupos e coletivos. São Paulo, SP: Hucitec. 
Benevides, R. (2005). A Psicologia e o Sistema Único de Saúde: quais interfaces? Psicologia \& Sociedade, 17(2), 21-25. https://doi.org/10.1590/S0102-71822005000200004

Bernardo, M. H., \& Pereira, M. S. (2017). O trabalho no contexto brasileiro atual e os compromissos da psicologia. In: E. F. Rasera. M. S. Pereira. D. C. G. Galindo (Orgs.), Democracia participativa, estado e laicidade: psicologia social e enfrentamentos em tempos de exceção (pp. 143-158). Porto Alegre, RS: Abrapso.

Bernardo, M. H., Sousa, C.C., \& Pinzón, J. G. (2013). Psicologia social do trabalho: Possibilidades de intervenções. In: M. H. Bernardo, R. S. L. Guzzo, \& V. L. T. Souza (Orgs.). Psicologia social: Perspectivas críticas de atuação e pesquisa (pp. 91-115). Campinas, SP: Alínea.

Bernardo, M. H., Sousa, C. C., Pinzón, J. G., \& Souza, H. A. (2015). A práxis da psicologia social do trabalho: Reflexões sobre possibilidades de intervenção. In: M. C. Coutinho, O. Furtado, \& T. R. Raitz (orgs.). Psicologia social e trabalho: Perspectivas críticas. (pp. 16-39). Florianópolis, SC: Abrapso.

Bernardo, M. H., Souza, H. A., Silva, D. L. D., \& Garbin, L. S. (2013). A psicologia e a saúde do trabalhador: Para além da prática hegemônica. In: M. H. Bernardo, R. S. L. Guzzo, \& V. L. T. Souza (Orgs.), Psicologia social: Perspectivas críticas de atuação e pesquisa (pp. 173-221). Campinas, SP: Alínea.

Blanch, J. M., \& Cantera, L. M. (2008). Subjetivación del trabajo en el capitalismo flexible. In: A. M. Mendes, Trabalho e saúde: O sujeito entre a emancipação e a servidão (pp. 89-101). Curitiba, PR: Juruá.

Bourdieu, P. (2012). O poder simbólico. Rio de Janeiro, RJ: Bertrand Brasil.

Bourdieu, P. (2011). O senso prático. Petrópolis, RJ:Vozes.

Bourdieu, P. (1989). Social space and simbolic power. Sociological Theory, 7(1), 14-25.

Diehl, R., Maraschin, C., \& Tittoni, J. (2006). Ferramentas para uma psicologia social. Psicologia em Estudo, 11(2), 407-415. https://doi.org/10.1590/S1413-73722006000200020.

Lei no 11.788, de 25 de setembro de 2008 (2008, 18 setembro). Dispõe sobre o estágio de estudantes. Diário Oficial da União.

Machado, A. M. (2014). Exercer a postura crítica: Desafios no estágio em psicologia escolar. Psicologia: Ciência e Profissão, 34(3), 760-773. https://doi.org/10.1590/1982-3703001112013

Maraschin, C., \& Tittoni, J. (2002). Cotidiano e configuração de espaços de aprendizagem. Educar, (19), 147-157. https://doi.org/10.1590/0104-4060.252

Marx, K. (2013). O capital: Crítica da economia política (Livro I: o processo de produção do capital). São Paulo, SP: Boitempo.

Mészáros, I. (2008). A educação para além do capital. São Paulo, SP: Boitempo.

Minayo-Gomez, C., \& Thedim-Costa, S. M. F. (1997). A construção do campo da saúde do trabalhador: percurso e dilemas. Cadernos de Saúde Pública, 13(Supl. 2), 21-32. https://doi.org/10.1590/S0102-311X1997000600003

Nasciutti, F. M. B., \& Silva, S. M. C. (2014). O processo de ensinar-aprender uma perspectiva crítica em psicologia escolar e educacional. Psicologia em Estudo, 19(1), 25-37. https://doi.org/10.1590/S1413-73722014000100005

Pereira, M. S. (2015). As concepções sobre saúde do trabalhador, as práticas profissionais e o contexto de atuação de psicólogos organizacionais (Tese de Doutorado não publicada). Universidade de São Paulo, São Paulo, SP, Brasil.

Pereira, M. S. (2017). Trabalho, vida e adoecimento: as múltiplas faces da violência contra trabalhadores. In: C. A. Fernandes (Org.). A volência na contemporaneidade, do simbólico ao letal (pp. 85-111). São Paulo, SP: Intermeios.

Peretta, A. A. C. S., Silva, S. M. C.,; Naves, F. F., Nasciutti, F. M. B., \& Silva, L. S. (2015). Novas diretrizes em tempos desafiadores: Formação em psicologia para atuar na educação. Revista Psicologia Escolar e Educacional, 19(3), 547-556. https://doi.org/10.1590/2175-3539/2015/0193893

Prilleltensky, I. (1994). Industrial/organizational psychology. In: I. Prilleltensy, Moral and politics of psychology: psychological discourse and the status quo. Albany: State University of New York Press.

Ramos, C. (2012). Tirando a venda dos espertos: Reflexões sobre a formação de psicólogos em tempos de cinismo. In: M. H. S. Patto (Org.), Formação de psicólogos e relações de poder: Sobre a miséria da psicologia (pp. 153-172). São Paulo, SP: Casa do Psicólogo. 
Reis, C., \& Guareschi, N. M. F. (2010). Encontros e desencontros entre psicologia e política: Formando, deformando e transformando profissionais da saúde. Psicologia: Ciência e Profissão, 30(4), 854-867. https://doi.org/10.1590/ S1414-98932010000400014

Resolução no 8, de 7 de maio de 2004 (2004, 18 maio). Institui as Diretrizes Curriculares Nacionais para os cursos de graduação em Psicologia. Diário Oficial da União.

Santos, A. P. S., \& Lacaz, F. A. C. (2011). Saúde do Trabalhador no SUS: Contexto, estratégias e desafios. In: C. M. Gomez, J. M. H. Machado, \& P. G. L. Pena. Saúde do trabalhador na sociedade brasileira contemporânea (pp. 87-105). Rio de Janeiro, RJ: Editora FIOCRUZ.

Zanella, A., Levitan, D., Almeida, G. B., \& Furtado, J. R. (2012). Sobre reXistências. Psicologia Política, 12 (24), 247-262.

Zanella, A. V., \& Sais, A. P. (2008). Reflexões sobre o pesquisar em psicologia como processo de criação ético, estético e político. Análise Psicológica, 4(26): 679-687.

\section{Maristela de Souza Pereira}

Professora Adjunta do Instituto de Psicologia da Universidade Federal de Uberlândia. Uberlândia - MG. Brasil.

E-mail: maristela.ufu@gmail.com

Andressa Fonseca Felice de Oliveira

Residente do Hospital de Clínicas da Faculdade de Medicina da Universidade de São Paulo. São Paulo - SP. Brasil.

E-mail : andressaffelice@gmail.com

\section{Jéssica Pagliarini Machado}

Mestranda do Programa de Pós-Graduação em Psicologia da Universidade Federal de Uberlândia. Uberlândia MG. Brasil.

E-mail : jpagliarinim@gmail.com

\section{Nágilla Regina Saraiva Vieira}

Mestranda do Programa de Pós-Graduação em Psicologia da Universidade Federal de Uberlândia. Uberlândia MG. Brasil.

E-mail: nagillavieira@gmail.com

\section{Raíssa Neves Miranda}

Graduada em Psicologia pela Universidade Federal de Uberlândia. Uberlândia - MG. Brasil.

E-mail: raissanmiranda@gmail.com

\section{Samantha Sousa Nascimento Cunha}

Graduada em Psicologia da Universidade Federal de Uberlândia. Uberlândia - MG. Brasil.

E-mail: samanthacun@gmail.com

\section{Tatyanne Couto Flor}

Graduada em Psicologia da Universidade Federal de Uberlândia. Uberlândia - MG. Brasil.

E-mail: tatyanneflor@gmail.com

Endereço para envio de correspondência:

Instituto de Psicologia - Universidade Federal de Uberlândia

Av. Pará, 1720, Bloco 2C, sala 34. Campus Umuarama. CEP: 38400-902.

Uberlândia - MG. Brasil. 
Recebido 11/07/2017

Reformulado30/11/2017

Aprovado 02/01/2018

Received $07 / 11 / 2017$

Reformulated $11 / 30 / 2017$

Approved 01/02/2017

Recibido 11/07/2017

Reformulado 30/11/2017

Aceptado 02/01/2017

Como citar: Pereira, M. S., Oliveira, A. F. F, Machado, J. P., Vieira, N. R. S., Miranda, R. N., ... Flor, T. C. (2018). Estágio profissionalizante e formação em Psicologia: $\mathrm{O}$ trabalho com grupos como dispositivo formativo. Psicologia: Ciência e Profissão, 38(2), 218-232. https:// doi.org/10.1590/1982-3703002752017

How to cite: Pereira, M. S., Oliveira, A. F. F, Machado, J. P., Vieira, N. R. S., Miranda, R. N., ... Flor, T. C. (2018). Professional Internship and Training in Psychology: Working with Groups as a Formative Device. Psicologia: Ciência e Profissão, 38(2), 218-232. https://doi.org/10.1590/1982-3703002752017

Cómo citar: Pereira, M. S., Oliveira, A. F. F., Machado, J. P., Vieira, N. R. S., Miranda, R. N., ... Flor, T. C. (2018). Prácticas profesionales y formación en Psicología: El trabajo con grupos como dispositivo formativo. Psicologia: Ciência e Profissão, 38(2), 218-232. https://doi.org/10.1590/1982-3703002752017 